\title{
Introduction to the special issue on maritime security: current and future challenges
}

\author{
Simon Véronneau ${ }^{1} \cdot K_{\text {Keenan D. Yoho }}{ }^{2}$
}

Published online: 7 December 2020

(C) This is a U.S. government work and not under copyright protection in the U.S.; foreign copyright protection may apply 2020

The objective of this special issue is to stimulate interest in, and advance the topic of, maritime security among researchers and practitioners alike. Despite being an important field of research with many needs still to be addressed, maritime security research is underrepresented in peer-reviewed scholarly journals. Like other security-related fields of research, there is the challenge of navigating between sharing important findings in the field with scholarly colleagues and giving away too much information to nefarious actors looking for ways to exploit the system to bad ends. In this special issue, we present nine papers that advance the field of maritime security. To do so, contributions to this special issue address both general and specific aspects of maritime transportation and threats to maritime commerce utilizing methodologies ranging from network modeling to represent maritime transport in terms of a multilayer network. to in-depth interviews with border and customs officials. The variety of topics represented here by these nine papers are at the very core of maritime security. We are grateful that this issue has attracted a diverse group of researchers from around the world. We have received many submissions and we thank all researchers that have expressed interest and submitted for this special issue.

The views expressed in this document are those of the authors and do not reflect the official policy or position of their respective institutions, the Department of Defense or the U.S. Government.

Simon Véronneau

sveronne@nps.edu

Keenan D. Yoho

kyoho@rollins.edu

1 Graduate School of Defense Management, Naval Postgraduate School, 1 University Circle, Monterey, CA 93908, USA

2 Roy E. Crummer Graduate School of Business, Rollins College, 1000 Holt Avenue, Winter Park, FL 32789, USA 


\section{Current and future maritime security risks and threats}

The piracy threat is one of the oldest and pervasive threats to commercial maritime activity and trade and it remains a threat today even after significant investments by multiple nations to eliminate it. Piracy has decreased in places like the Gulf of Aden where maritime crime was a reflection of the bankrupt, lawless criminality to be found ashore in Somalia. Through deliberate investments, persistent patrolling and high-visibility security presence by the United Nations, European Union, independent European nations, the United States, and Gulf States nations, piracy has subsided. Total piracy attacks in the Gulf of Aden and the vicinity of Somalia have dropped from a peak of 166 attacks in 2011 to 1 attack in 2019 as reported by the European Union (EU) naval task force in Somalia.

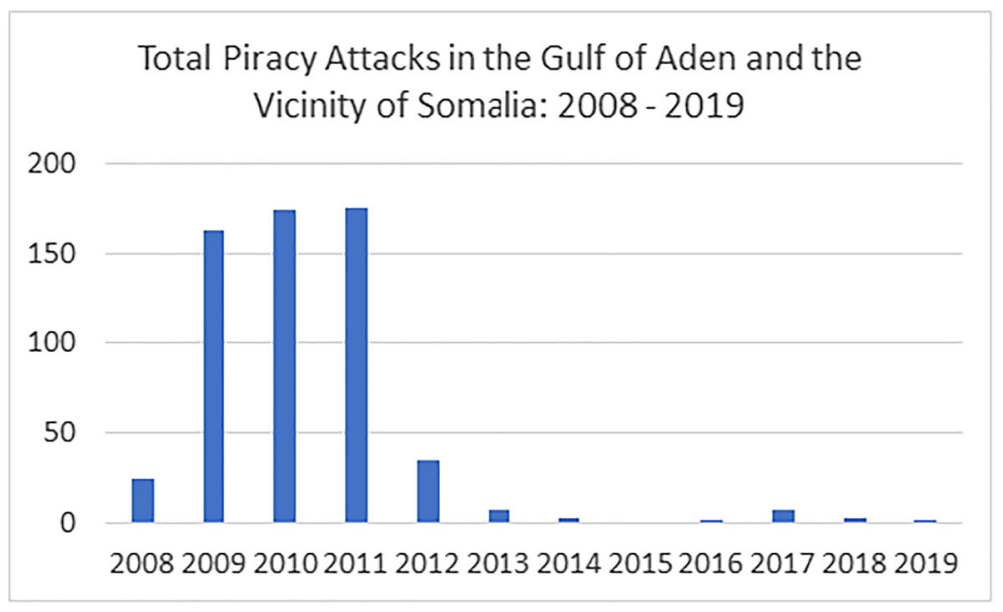

Total piracy attacks in the Gulf of Aden and Vicinity of Somalia from 2008 to 2009 (Source: EU Naval Force-Somalia Operation ATALANTA)

However, piracy activity has shifted to West Africa where it has risen dramatically in the Gulf of Guinea off the coast of Nigeria. Of 162 world-wide piracy attacks reported to the International Maritime Bureau in 2019, 64 of those attacks occurred in the Gulf of Guinea off Nigeria. According to the International Maritime Bureau, more than $90 \%$ of the global kidnappings reported at sea occur in the Gulf of Guinea and the total number of crew kidnapped in 2019 increased by 50\% from 78 in 2018 to 121 in 2019 (IMB, 2020). 


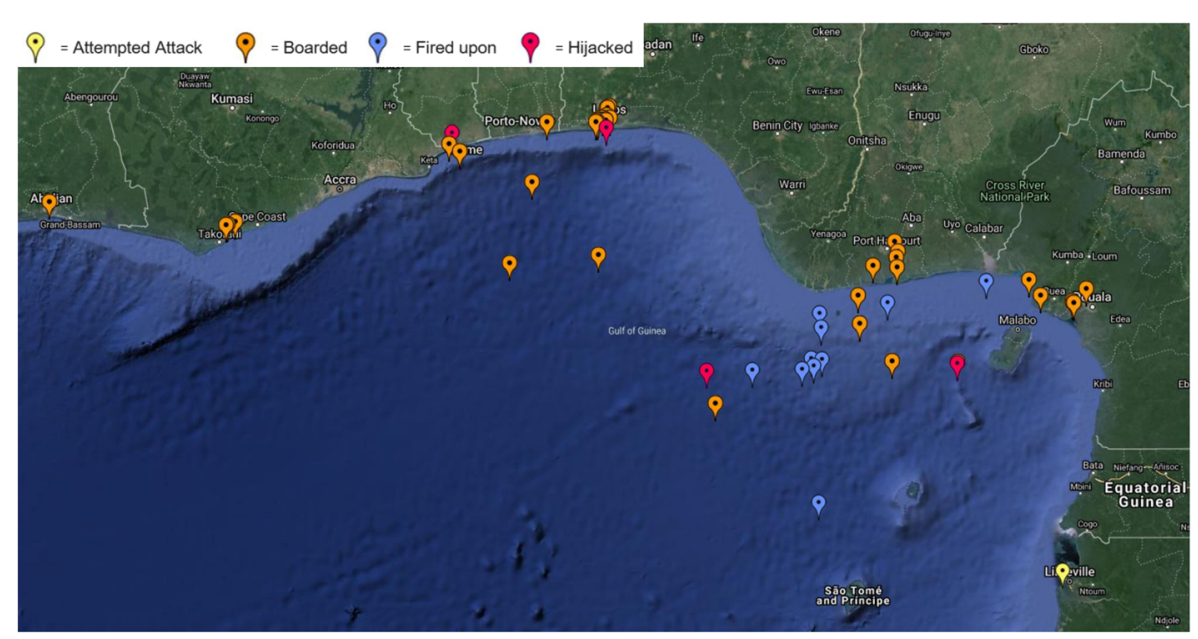

Total attacks in the Gulf of Guinea - January 1 to December 21, 2019 (Source IMB, 2020)

The total attempted or actual maritime attacks in the vicinity of the coast of the continent of Africa in 2019 was 71 with 64 of those occurring in the Gulf of Guinea and more than half of those - 35 - occurring in the vicinity of Nigeria. It is anticipated that piracy will continue to be a danger wherever the seas have valuable commercial traffic and remain largely ungoverned due to lack of naval or coast guard forces. As countries develop, and their territorial waters experience more commercial traffic, maritime domain awareness and accompanying maritime resources that are able to maintain security will be essential for curbing piracy.

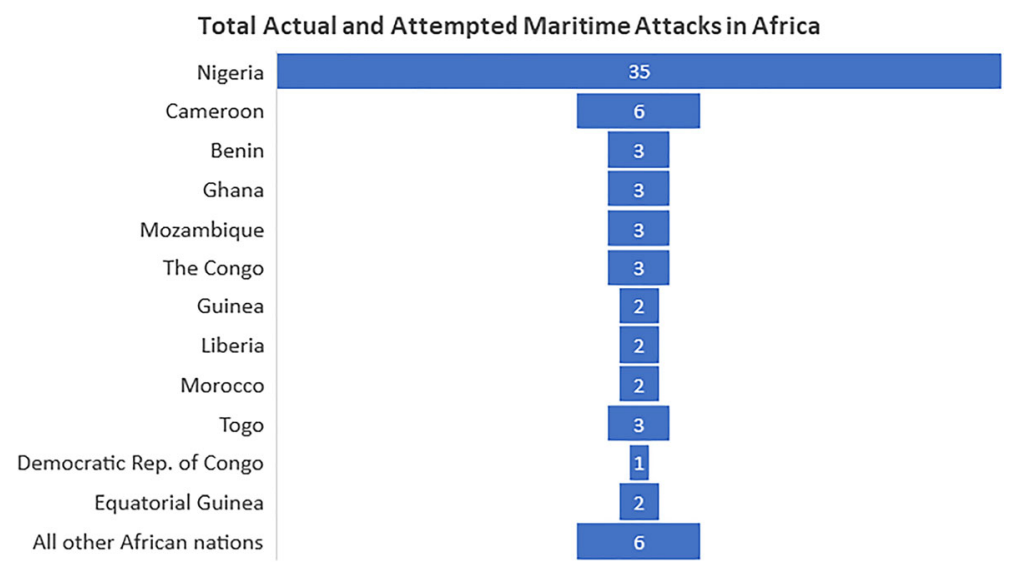

Total actual or attempted maritime attacks in the vicinity of the coast of the continent of Africa in 2019 (Source: IMB, 2020)

While piracy is an immediate and more obvious threat, cyber attacks are a type of threat that will increase in the future. As maritime vessels employ more systems that are connected to a global network, visibility, automation, and communication will become more ubiquitous while making commerce cheaper and faster. A consequence of this connectivity will be its vulnerability to cyber attack. Navigation, automatic guidance, 
and Electronic Chart Display and Information Systems (ECDIS) are already vulnerable to cyber attack by both state and non-state actors and as these systems become more pervasive and interconnected it will become easier to access them and either compromise or corrupt the information in them or take control of them.

As the operational tempo of maritime commerce increases in order to reduce costs and connect more geographic areas to trade, there will be increasing opportunities to compromise a vessel and its crew or cargo during the course of a particular journey. For containerized cargo, there will be increasing vulnerabilities between the point of embarkation and the point of debarkation for theft, compromise, or insertion of weapons that could harm people or infrastructure. For passenger and military vessels, husbanding services represent a potential threat as these providers have unprecedented access to the vessels and their crew and visibility into the activity of these providers, and the background of their workers, can often be low.

The opportunity to obstruct or compromise maritime trade is not equal everywhere. There are specific areas, choke points, or nodes where there will be greater vulnerability than others and this highlights the importance of seeing where those locations are and developing countermeasures or enhanced security protocols. The map of these choke points and nodes is likely to change as the Arctic opens up and there is increasing maritime activity in this previously impassable area. The ability to model these changes and then assess the consequences will become all the more important in the future.

\section{Contributions to the special issue}

We now introduce each of the papers for the special issue and touch briefly upon their theme and contribution. The first two papers in this issue deal with a threat that is many centuries old: Piracy. Hamza and Priotti discuss maritime trade and piracy in the Gulf of Aden and the Indian Ocean in their paper Maritime Trade and Piracy in the Gulf of Aden and the Indian Ocean (1994-2017). This work provides a historical perspective of current threats and realities in the Gulf of Aden and Indian Ocean region off the Horn of Africa. The authors note that while Piracy has received considerable attention in the beginning of the century, the general public awareness and interest in piracy is waning again. This is in part due to recent success of international cooperation efforts at sea and on land. However, the authors note the importance of maintaining vigilance with respect to piracy to prevent cooperation efforts and resources allocated to them from diminishing. The second paper from Nwalozie thematically explores contemporary piracy in the African state of Nigeria. The Gulf of Guinea and the Niger Delta Region have been known to be one of the worst hot spots for piracy and maritime criminality for some time (Anonymous 2014, 2019). Piracy activities in Nigeria are concentrated in oil and gas drilling sites in the Niger Delta region, Nwalozie draws connections between low socioeconomic status and the demographic makeup of the region and piracy by pointing out that "unemployed youths of the region use piracy activities as a fightback against the so-called 'resource control' embarked upon by the Federal Government of Nigeria, which disadvantages them." What Nwalozie describes is also an illustration of what political scientists, sociologists, economists, and historians refer to as the "resource curse" (Ross 1999) which describes countries with an abundance of natural resources that nevertheless are impoverished economically, are less democratic, 
and have worse development outcomes than similar countries with fewer extractable resources. Given the resource abundance of the Gulf of Guinea and Niger Delta, and the abundance of poor, fighting age individuals that may be attracted to the opportunities presented by the vocation of piracy, careful consideration of effective measures to thwart criminality as well as eliminate piracy in the region is needed as its effects are both regional and global in nature.

The third paper of the special issue is from Karahalios who employs a risk-based methodology to evaluate cybersecurity threats in the context of a piracy attack. After auditing 15 ships with 315 seafarers, Karahalios finds evidence of significant security gaps in the cybersecurity systems related to global positioning and navigation as well as loss of data related to cargo characteristics, destination, and commercial value to name a few. Additionally, there is a host of sensitive data in maritime shipping that is vulnerable to compromise through a cyber-attack to include time schedules, crew names and contact details, the number and professional qualifications of guards, and freeboard passport details (Karahalios). The fourth paper from Svilicic et al. also assesses cyber risk in an analysis of the cyber security weaknesses of the Electronic Chart Display and Information System (ECDIS) which is the backbone of paperless ship navigation around the world. The authors use an industry vulnerability scanner tool to detect potential vulnerabilities and highlight how critical cyber threat vectors result from uncontrolled internetworking of unmaintained ECDIS workstations with identical hardware and software configurations.

The fifth contribution from Wardin addresses passenger transport in the Baltic Sea and its vulnerability to terrorist attacks. Wardin discusses the threat posed by returning citizens who may travel abroad to fight as members of a terrorist organization - often defined as foreign fighters in the region of conflict - as well as citizens who may be radicalized and the threat they could pose to maritime passenger traffic in the Baltic region. Though Wardin's analysis is specific in its geography, the conclusions and recommendations are more general with respect to measures that may be taken using current technology and making some organizational changes to increase the security of maritime passengers. Not only will passenger transport be increasingly vulnerable to threats but containerized cargo, too, will be subject to increasing vulnerability. The sixth paper in this issue by Young and Gordon employs a thorough qualitative approach whereby the authors interview subject matter experts and public officials from regulatory agencies, transportation providers, importers, exporters, and trade intermediaries to decompose the global maritime supply chain into critical points before goods are cleared by U.S. Customs. Young and Gordon conclude, from a maritime security perspective, that the greatest vulnerabilities to containerized cargo lie in those transportation segments between the origin of the goods and when they await shipment at a foreign port.

A special issue in maritime security would not be complete without some discussion of the danger and hazards associated with the mariner profession. The seventh paper in this issue from Liwång studies fatalities on board military vessels as a result of accidents and antagonistic attacks to understand the determinants of safety, operability, and recoverability. Using operations in the Falklands War, antagonistic attacks in operations other than declared war from 2000 to 2012, submarine incidents from 2000 to 2015, and severe accidents in Norway and Sweden from 1990 to 2015 as cases, Liwång shows that though 
different types of operations have distinct levels of risk, there is commonality with respect to safety issues and that recoverability is determined by the capacity of the crew to take effective action when management and oversight may be limited. The eighth paper in this special issue investigates the role of husbanding service providers (HSPs) in providing logistics support to the United States Navy. Elliott et al. identify the types of sensitive information HSPs have access to and the importance of vetting HSPs to maintain operational security. The authors provide an overview of the operational security implications of contracting HSPs to serve the U.S. Navy abroad and how the prevalence of corruption combined with the spread of terrorism and the increasingly expansive reach of China has increased the risk exposure to the U.S. Navy vis-à-vis its HSPs. Finally, in the ninth and final paper in this special issue, Alderson et al. model the global maritime transportation system as a multilayer network of sea routes and land routes that work together to deliver cargo on a global scale. The authors then use their layered network to identify important nodes from a connectivity standpoint. This work has broad implications in that it identifies important places and routes that are critical to maritime commerce and that require safeguarding and protecting if global trade is to remain undisrupted. Today and, more critically, in the future it will be necessary to not only have a sense of where the critical geographic maritime bottlenecks and choke points are but also where the future opportunities and perils lie. Current choke points such as the Strait of Hormuz present dangers such as rocket attacks from Iran or Iranian-backed agents. But future maritime passages such as the Arctic and High North present opportunities and dangers as the United States, Canada, Russia, Norway, Denmark, Iceland, Sweden, and Finland all have territorial interests at stake with Russia having the longest Arctic coastline that extends more than ten thousand miles (Masters 2013). China also has a strong economic interest in access to the High North as it will become a major commercial artery as well as strategic one that it cannot ignore. The opportunity for all manner of conflict will be ripe in the coming years and this work by Alderson et al. illuminates the topography of where vulnerability and potential conflict may arise.

We would like to thank the many contributors to this special issue. There were many interesting and substantive submissions and we believe those that appear here extend important lines of inquiry or open new areas of exploration in the area of maritime security. As the reader will find, this special issue addresses a wide variety of security aspects within the maritime security realm by bringing together researchers from Europe, Africa and North America to provide detail and data to some specific challenges. As the value of maritime commerce grows and is predicted to double by 2025 (U.S. Coast Guard 2018), the importance of safeguarding this commerce while also enabling its flow will grow as well. We would like to extend our thanks to the Editor in Chief for the patience and encouragement that was extended to see that this expansive special issue was published. We hope this issue will motivate other researchers to pursue more research in maritime security while also informing the varied stakeholders in maritime activity.

Simon Véronneau, Ph.D.

Associate Professor of Operations Management. 
Graduate School of Defense Management.

Naval Postgraduate School.

Keenan D. Yoho, Ph.D.

Professor of Operations Management.

Roy E. Crummer Graduate School of Business.

Rollins College.

\section{References}

Anonymous (2014) The ungoverned seas; piracy in Africa. The Economist 413:43-44

Anonymous (2019) Crime waves: the Gulf of Guinea is now the world's worst piracy hotspot. The Economist 431:59-60

International Maritime Bureau (IMB) (2020) Piracy and armed robbery against ships, Annual Piracy Reports, International Commercial Crime Services, London, United Kingdom

Masters J (2013) The Thawing Arctic: Risks and Opportunities. Council on Foreign Relations, Washington, D.C. Accessed 04 Oct 2020 at: https://www.cfr.org/backgrounder/thawing-arctic-risks-and-opportunities Ross ML (1999) The political economy of the resource curse. World Polit 51:297-322

U.S. Coast Guard (2018) U.S. Coast Guard Maritime Commerce Strategic Outlook, U.S. Coast Guard Headquarters, Office of Emerging Policy, Washington, D.C.

Publisher's note Springer Nature remains neutral with regard to jurisdictional claims in published maps and institutional affiliations. 